\title{
Existence of Cervical Discopathy in Non-Cyclic Mastodynia
}

\author{
Mustafa Alimoğulları Hakan Buluş \\ Department of General Surgery, Keçioren Training and Research Hospital, University of Medical Sciences, Ankara, Turkey
}

\section{Keywords}

Breast · Bulging · Discopathy $\cdot$ Mastodynia .

Magnetic resonance imaging

\begin{abstract}
Background: Mastodynia is a subjective symptom that impairs the quality of life. It may be directly related with breast disorders. Moreover, a substantial rate is caused of reflective pain. Objectives: Non-cyclic mastodynia is multifactorial, and treatment should be planned according to the underlying cause. In this study, we aim to evaluate the existence of cervical discopathy via cervical magnetic resonance imaging (MRI) in the etiology of non-cyclic mastodynia. Methods: The study included 60 patients with normal physical examination results and imaging findings. Management was determined individually in patients. Patients with pathological MRI findings were evaluated by physical therapy, rehabilitation, and neurosurgery specialists, and appropriate treatment was planned. Patients were evaluated with the visual analogue scale (VAS) scoring system at initial presentation and after 1 and 3 months of treatment. Results: The majority of patients had positive findings on MRI (53 [88.4\%] vs. 7 [11.6\%]). The mean VAS scores at the time of presentation, after 1, and after 3 months of treatment were 7.41,6.39, and 3.35 , respectively. The decrease in the scores was statistically significant $(p \leq 0,01)$. Conclusions: We suggest that cervical discopathy should be kept in mind in cases of idiopathic non-cyclic mastodynia. Furthermore, cervical discopathy-related mastodynia seems to have a good response to appropriate treatment.

(c) 2019 S. Karger AG, Basel
\end{abstract}

\section{Introduction}

The term mastodynia (mastalgia) was first used by Billroth to describe "breast pain" [1]. Mastodynia also describes tightness, soreness, and the sense of tenderness on one or both breasts in addition to nipple pain [2]. To explain the reason of breast pain, authors suggest different theories such as excess estrogen, progesterone deficiency, distribution of progesterone-estrogen ratio, etc. [3, 4]. Mastodynia is frequently related to benign causes but can also present in breast cancers [5].

Mastodynia is classified into three groups: cyclic, noncyclic, and extramammary [6]. One-third of the patients have non-cyclic mastodynia. It is important to determine the type of pain because both evaluation and treatment differ.

Non-cyclic mastodynia is defined as constant breast pain independent from the menstrual cycle. This occurs in about $31 \%$ of the women who come to clinics with breast pain [6]. It is mostly a complaint of 40-to-50-yearold and postmenopausal women but can also be observed in premenopausal women at reproductive ages $[3,6,7]$. Breast pain can be severe and may disturb daily activities and affect the quality of life [8].

The cause of extramammary pain is usually costochondritis, or the pain originates from the thoracic wall $[6,9]$. The etiology of musculoskeletal breast pain includes thoracic wall syndromes, costochondritis, and Tietze syndrome [10]. Cervical disc hernia is a cause of extramammary pain that is generally disregarded by clinicians. During pain assessment, all of these should be considered. In 
Table 1. Initial, 1-month, and 3-month VAS scores

\begin{tabular}{|c|c|c|c|c|c|c|}
\hline \multirow{3}{*}{$\begin{array}{l}\text { VAS } \\
\text { score } \\
\\
0\end{array}$} & \multirow{2}{*}{\multicolumn{2}{|c|}{$\begin{array}{l}\text { Initial VAS } \\
\text { scores } \\
\text { patient No. \% }\end{array}$}} & \multirow{2}{*}{\multicolumn{2}{|c|}{$\begin{array}{l}\text { 1-month } \\
\text { control VAS } \\
\text { scores } \\
\text { patient No.\% }\end{array}$}} & \multicolumn{2}{|c|}{$\begin{array}{l}\text { 3-month control } \\
\text { VAS scores }\end{array}$} \\
\hline & & & & & \multicolumn{2}{|c|}{ patient No. $\%$} \\
\hline & - & - & - & - & 9 & 17.0 \\
\hline 1 & - & - & - & - & 6 & 11.3 \\
\hline 2 & - & - & - & - & 10 & 18.9 \\
\hline 3 & - & - & - & - & 6 & 11.3 \\
\hline 4 & - & - & 2 & 3.8 & 6 & 11.3 \\
\hline 5 & 2 & 3.8 & 12 & 22.6 & 6 & 11.3 \\
\hline 6 & 4 & 7.5 & 19 & 35.8 & - & - \\
\hline 7 & 25 & 47.2 & 7 & 13.2 & 4 & 7.5 \\
\hline 8 & 14 & 26.4 & 9 & 17.0 & 2 & 3.8 \\
\hline 9 & 8 & 15.1 & 4 & 7.5 & 4 & 7.5 \\
\hline 10 & - & - & - & - & - & - \\
\hline
\end{tabular}

VAS, visual analogue scale.

this study, we aim to evaluate the existence of cervical discopathy via magnetic resonance imaging (MRI) in the etiology of non-cyclic idiopathic mastodynia.

\section{Materials and Methods}

This study included 67 females with non-cyclic mastodynia. Patients with a daily and continuous pain were determined as study candidates. Patients with a family history of breast cancer, a history of any kind of oral contraceptive, anticoagulant, or antidepressant drug use, hormone replacement therapy, or trauma were excluded. Pregnant or lactating females and male patients were also excluded. Patients ( $>40$ years of age) with normal ultrasonography and/or mammography findings were included.

All patients were evaluated with cervical MRI. Patients who had a pathological finding on MRI were referred to physical therapy and rehabilitation and neurosurgery specialists. In conservative therapy, the patients were prescribed neck exercise for 2 weeks and oral diclofenac sodium $(2 \times 75 \mathrm{mg} /$ day $)$ and mefenoksalon $(2 \times 400$ $\mathrm{mg} /$ day) for the first 5 days. A surgical approach (posterior cervical discectomy operation) was needed in 1 patient. Patients were evaluated at initial presentation and after 1 and 3 months of the treatment. During evaluation, the visual analogue scale (VAS) was used for pain scoring.

Statistical analyses of the study results were performed using the SPSS v.15.0 (Statistical Package for Social Sciences, Chicago, IL, USA) software. To compare statistical differences between binary groups, the Wilcoxon test was used. $p$ values $<0.05$ was considered statistically significant.

\section{Results}

Patients with inadequate adherence to therapy $(n=7)$ were excluded, and the study was composed of $60 \mathrm{pa}-$ tients. The mean age and menarche age of the patients were $47.9 \pm 12.8$ and $12.9 \pm 0.854$, respectively. Post-
Table 2. Wilcoxon test VAS averages

\begin{tabular}{|c|c|c|c|}
\hline & $\begin{array}{l}\text { Initial } \\
\text { VAS-VAS } 1\end{array}$ & $\begin{array}{l}\text { VAS 1- } \\
\text { VAS } 3\end{array}$ & $\begin{array}{l}\text { Initial } \\
\text { VAS-VAS } 3\end{array}$ \\
\hline VAS score & $7.41-6.39$ & $6.39-3.35$ & $7.41-3.35$ \\
\hline$Z$ & $-5.297 \mathrm{a}$ & $-5.494 a$ & $-5.740 a$ \\
\hline Asymp. Sig. (2-tailed) & 0.000 & 0.000 & 0.000 \\
\hline
\end{tabular}

VAS, visual analogue scale; VAS 1, VAS at 1 month; VAS 3, VAS at 3 months; a, based on negative ranks; Asymp. Sig., asymptotic significance.

menopausal women constituted the greater part of the study (44 [73.3\%] vs. 16 [26.6\%]). The mean parity number was $2.77 \pm 1.28$. In our study, only $2(3.3 \%)$ of the patients were nulliparous and thus had no history of lactation. The mean duration of breast pain was $20.6 \pm 24.8$ months. It was detected that $22(36.6 \%)$ patients felt the pain was more remarkable in the right breast, whereas for $38(63.4 \%)$ patients, the pain was more in the left breast.

No pathological findings were encountered in the MRI of $7(11.6 \%)$ patients. Pathological findings were present in $53(88.4 \%)$ patients, including diffuse annular bulging on various cervical levels $(n=39[65 \%])$ and both diffuse annular bulging and cervical disc protrusion $(n=14[23.3 \%])$.

In 53 patients who had a pathological finding on MRI, $36(67.9 \%)$ patients had various degrees of sensory loss, weakness, tingling, neck, shoulder and arm pain. No symptoms of discopathy were determined in the remaining $17(32.1 \%)$ patients.

Of the total study population, $52(86.7 \%)$ were prescribed conservative treatment, and 1 patient underwent posterior cervical discectomy operation. No treatment was recommended for the 7 (11.7\%) patients without cervical MRI findings.

The VAS score of the 53 patients who received treatment because of determined pathological MRI findings was $7.41 \pm 0.96$ at initial presentation, $6.39 \pm 1.32$ after 1 month of treatment, and $3.35 \pm 2.76$ after 3 months of treatment (Table 1). The decrease in the VAS score was found to be statistically significant $(p<0.01)$.

The 1-month VAS score was statistically significantly lower than the mean VAS score of the first examination $(p<0.01)$. Furthermore, the mean VAS score after 3 months was statistically significantly lower than the mean VAS score after 1 month $(p<0.01)$ (Table 2).

\section{Discussion}

Mastodynia is a condition that adversely effects women's daily every-day activities and leads to considerable costs. Existing studies show that $48 \%$ of these patients 
have been adversely affected in their sexual life. Besides this, it is also reported that patients were affected in their physical, social, and occupational/school activities $[8,11$, $12]$. The mean age for non-cyclic mastodynia is generally around 40-50 years $[6,7]$. In our study, the mean age of the patients was $47.96 \pm 12.8$, and these findings are in agreement with the literature.

A cohort study with 2,400 patients examined over the period of 10 years has shown that the most common symptom regarding the breasts is mastodynia [13]. Davies et al. [14] reported that $68.5 \%$ of the patients have cyclic mastodynia, and $31.5 \%$ have non-cyclic mastodynia. A study of 253 patients by Wisbey et al. [15] found similar results as Davies et al. [14], with two-thirds of the patients having cyclic pain.

Olawaiye et al. [16] reported that almost all patients who have non-cyclic mastodynia need treatment, and after discontinuing the treatment, the recurrence rate of pain is $60 \%$. In another study conducted over a period of 15 years, the complaints have persisted in $64 \%$ of the patients with non-cyclic mastodynia. The same study demonstrates that non-cyclic mastodynia is less likely to have a hormonal association than cyclic mastodynia, and response to treatment is lower [14]. A psychological origin may also be the underlying reason for breast pain. In these patients, organic causes should be kept in mind in case of failure of the suggested therapy. This is another reason why we included patients with non-cyclic mastodynia.

In a study that evaluates the coexistence of fibromyalgia and mastodynia, it was shown that $36 \%$ of the mastodynia patients concurrently had fibromyalgia. Moreover, $42 \%$ of the fibromyalgia patients had the complaint of mastodynia [17].

It has been demonstrated that $86.5 \%$ of the patients with breast pain have radiologically normal findings, $8.6 \%$ had benign abnormalities, $3.6 \%$ had probably benign abnormalities, $0.8 \%$ had suspicious findings, and $0.4 \%$ had cancer [18]. This indicates that the probability for an extramammary pain origin is higher in patients with no organic breast pathology. Cervical discopathy is a common disorder with an incidence of 83.2 per 100.000 [19]. In Turkey, cervical discopathy is a common disorder among women. This was the main reason that directed us to investigate the relationship between cervical discopathy and mastodynia.

In our study, non-cyclic mastodynia patients who had pathological findings on cervical MRI clearly benefited from treatment for cervical discopathy. Because of the fact that there is no other scientific study about the subject, we could not make any comparisons. Our opinion is that more studies should be conducted about this topic. The prospective structure and strict patient selection are the strengths of our study. The small number of patients can be considered a limitation of the study.

\section{Conclusion}

It is important to treat breast pain according to the underlying cause. Non-cyclic mastodynia without any organic pathologies in the breasts should be investigated for cervical discopathy. We think that cervical vertebral pathologies should be considered in the etiology of noncyclic mastodynia, and the good response in our study raises hope for the treatment of discopathy-associated mastodynia. Larger prospective series concerning this issue would contribute to the literature.

\section{Statement of Ethics}

The study was approved by the institutional ethics committee. Approval No.: 042012/60.

\section{Disclosure Statement}

The authors declare that there are no conflicts of interest, financial or otherwise, related to the material presented herein.

\section{References}

1 Grimm K, Fritsche E. [Reduction of Breasts ... Hans Schaller and the first mammoplasty in 1561. Contribution to history of medicine]. Handchir Mikrochir Plast Chir. 2000 Sep; 32(5):316-20.

2 Gregl A. [Conservative Therapy of Mastopathy (Mastodynia)]. Med Welt. 1979 Feb; 30(7):264-8.

3 Bland EM. Copeland. The Breast: Comprehensive Management of Benign and Malignant Diseases. 2nd ed. Pennsylvania: W.B. Saunders Company; 1998. pp. 247-60.

4 Cole EN, Sellwood RA, England PC, Griffiths K. Serum prolactin concentrations in benign breast disease throughout the menstrual cycle. Eur J Cancer. 1997 Jun;13(6):597-603.

5 Türkan A, Akkurt G, Yalaza M, Değirmencioğlu G, Kafadar MT, Yenidünya $\mathrm{S}$, et al. Effect of LigaSureTM, Monopolar Cautery, and Bipolar Cautery on Surgical Margins in Breast-Conserving Surgery. Breast Care. DOI: 10.1159/000493985.

6 BeLieu RM. Mastodynia. Obstet Gynecol Clin North Am. 1994 Sep;21(3):461-77.

7 Mansel RE. ABC of breast diseases. Breast pain. BMJ. 1994 Oct;309(6958):866-8.

8 Ader DN, Shriver CD, Browne MW. Relationship of cyclical mastalgia. Premenstrual syndrome or recurrent pain disorder. Am J Obstet Gynecol. 1997;20:198-202.

9 Maddox PR, Harrison BJ, Mansel RE, Hughes LE. Non-cyclical mastalgia: an improved classification and treatment. Br J Surg. 1989 Sep; 76(9):901-4.

10 Fam AG. Approach to musculoskeletal chest wall pain. Prim Care. 1988 Dec;15(4):767-82.

11 Ader DN, Shriver CD. Cyclical mastalgia: prevalence and impact in an outpatient breast clinic sample. J Am Coll Surg. 1997 Nov; 185(5):466-70.

12 Faiz O, Fentiman IS. Management of breast pain. Int J Clin Pract. 2000 May;54(4):228-32. 
13 Smith RL, Pruthi S, Fitzpatrick LA. Evaluation and management of breast pain. Mayo Clin Proc. 2004 Mar;79(3):353-72.

14 Davies EL, Gateley CA, Miers M, Mansel RE. The long-term course of mastalgia. J R Soc Med. 1998 Sep;91(9):462-4.

15 Wisbey JR, Kumar S, Mansel RE, Peece PE, Pye JK, Hughes LE. Natural history of breast pain. Lancet. 1983 Sep;2(8351):672-4.
16 Olawaiye A, Withiam-Leitch M, Danakas G, Kahn K. Mastalgia: a review of management. J Reprod Med. 2005 Dec;50(12):933-9.

17 Genç V, Genç A, Ustuner E, Düşünceli EB, Oztuna D, Bayar S, et al. Is there an association between mastalgia and fibromyalgia? Comparing prevalence and symptom severity. Breast. 2011 Aug;20(4):314-8.
18 Jokich PM, Bailey L, D’Orsi C, Green ED, Holbrook AI, Lee SJ, et al.; Expert Panel on Breast Imaging. ACR Appropriateness Criteria ${ }^{\circledR}$ Breast Pain. J Am Coll Radiol. 2017 May; 14(5 5S):S25-33.

19 Usta B, Muslu B, Demircioğlu RI, Sert H, Gözdemir M, Karabayirli S. [Cervical epidural steroid injections for symptomatic disc herniations]. Agri. 2012;24(3):130-4. 